\title{
The Effectiveness of Balance Training Programs on Reducing the Incidence of Ankle Sprains in Adolescent Athletes
}

\author{
Tamara C. Valovich McLeod
}

\section{Clinical Scenario}

Ankle sprains are one of the most common sport-related injuries treated by rehabilitation professionals. These injuries often result in lost participation and can lead to subsequent injury episodes. Therefore, it is important to determine appropriate means of preventing these injuries. There has recently been an increase in the popularity of balance training programs for the prevention of knee anterior cruciate ligament (ACL) injury, with some thought that starting these programs in younger athletes may be most beneficial. However, there is the potential that these types of training programs may also be beneficial for decreasing the risk of other lower extremity injuries, including ankle sprains in the adolescent athlete.

\section{Focused Clinical Question}

Are balance training programs effective at reducing ankle sprain injury rates in adolescent athletes?

\section{Summary of Search, "Best Evidence" appraised, and Key Findings}

- The literature was searched for studies of level 2 evidence or higher that investigated the effect of balance or proprioceptive training programs on ankle sprain incidence in adolescent athletes.

- Two high quality RCT and 2 cohort studies were included.

- Two studies demonstrated reductions in ankle sprain injury rates following balance training programs that included preseason and in-season supervised sessions. 
- Differences were not noted between control subjects and those that participated in either a home-based or an in-season only balance training program.

- Subject compliance was higher in the two studies that had supervised training sessions.

\section{Clinical Bottom Line}

There is moderate evidence to support the use of a supervised balance training program that includes both preseason and in-season supervised sessions to reduce the rate of ankle sprains in adolescent athletes.

Strength of Recommendation. Level B evidence exists that supervised preseason and in-season balance training programs are effective in reducing the rate of ankle sprains in adolescent athletes.

\section{Search Strategy}

\section{Terms Used to Guide Search Strategy}

- Patient/Client Group: adolescent OR high school AND athlete

- Intervention (or Assessment): balance OR proprioception OR training AND prevention,

- Comparison: no intervention AND control

- Outcome(s): ankle injury AND incidence OR risk

\section{Sources of Evidence Searched}

- The Cochrane Library

- PEDro Database

- Medline

- CINAHL

- Sport Discus

- Additional resources obtained via review of reference lists and hand search

\section{Inclusion and Exclusion Criteria}

\section{Inclusion}

- Studies investigating multiple lower extremity injury rates if subanalyses for ankle sprains were reported.

- Level 2 evidence or higher

- Limited to English language

- Limited to humans

- Limited to the last 10 years (1998-2008) 


\section{Exclusion}

- Studies using multi-component programs (balance + plyometrics and/or strength, etc)

- Mixed subject pool (adult and adolescent)

\section{Results of Search}

Four relevant studies ${ }^{1,2,3,4}$ were located and categorized as shown in Table 1 (based on Levels of Evidence, Centre for Evidence Based Medicine, 1998).

One additional study ${ }^{5}$ investigating balance training and injury prevention in adolescents was located but not included in this CAT because the results did not provide enough data to compare relative risk specific to ankles sprains.

\section{Best Evidence}

The following studies were identified as the "best" evidence and selected for inclusion in the CAT (Table 2). Reasons for selecting these studies were because they were graded with a level of evidence of 2 or higher, studied a balance training intervention in adolescent athletes, and described the effect of the intervention on the outcome of interest (rate of ankle sprain injuries).

\section{Implications for Practice, Education and Future Research}

Only $2^{2,3}$ of the 4 studies reviewed in this CAT demonstrated a significant reduction in ankle sprain injury risk. These findings indicate that in general, balance training programs are moderately effective in reducing the risk of ankle sprains in adolescent athletes. There were some important differences in the design of the balance training programs that may have resulted in the aforementioned findings, including

\section{Table 1 Summary of Study Designs of Articles Retrieved}

\begin{tabular}{lccc}
\hline $\begin{array}{l}\text { Level of } \\
\text { Evidence }\end{array}$ & $\begin{array}{c}\text { Study Design/ } \\
\text { Methodology }\end{array}$ & $\begin{array}{c}\text { Number } \\
\text { Located }\end{array}$ & Author (Year) \\
\hline $1 \mathrm{~b}$ & RCT & 2 & $\begin{array}{c}\text { Emery et al (2007) } \\
\text { McGuine et al } \\
(2006)^{2} \\
2 \mathrm{~b}\end{array}$ \\
Cohort & 2 & $\begin{array}{c}\text { McHugh et al } \\
(2007)^{3} \\
\text { Malliou et al } \\
(2004)^{4}\end{array}$ \\
\hline
\end{tabular}




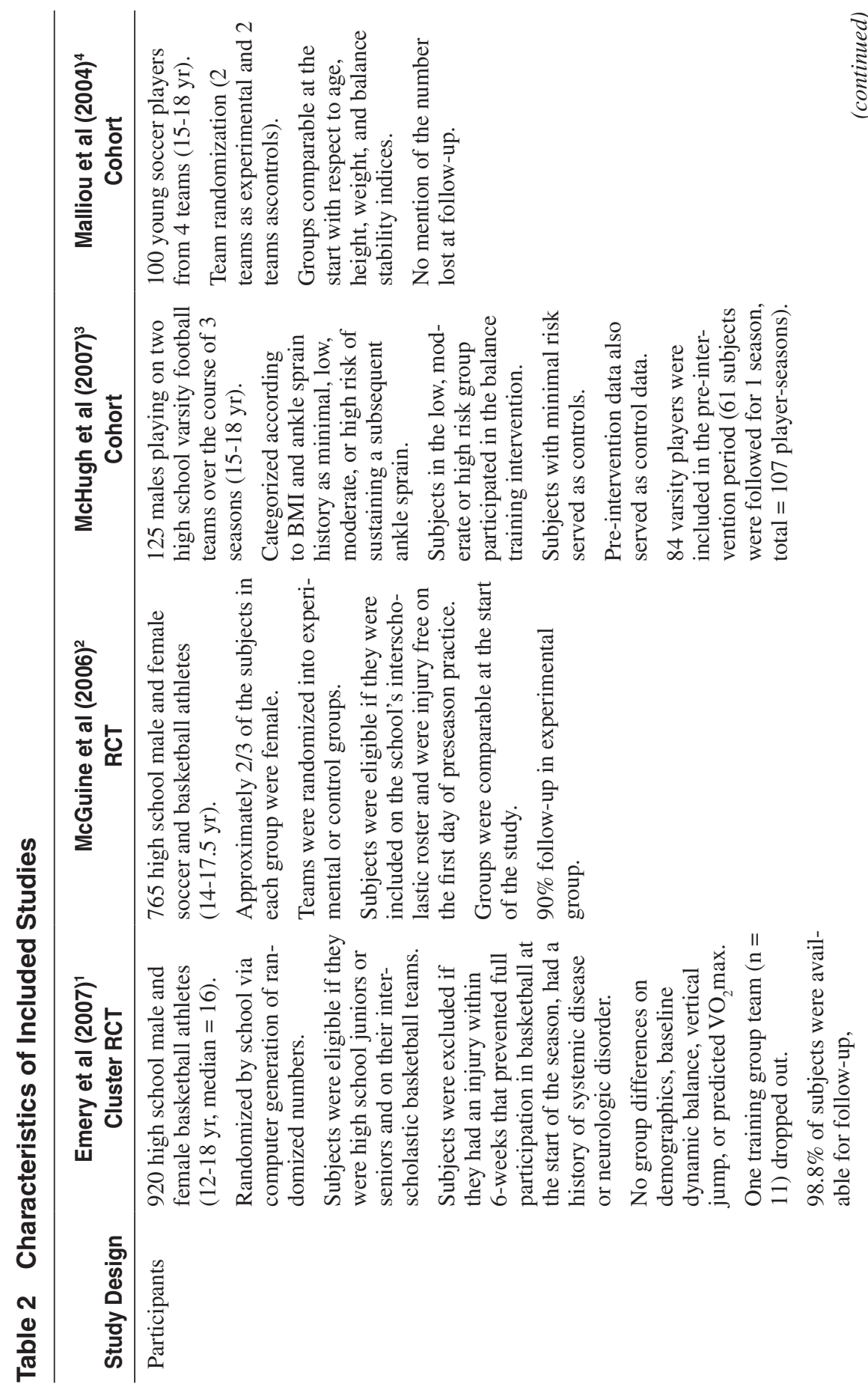




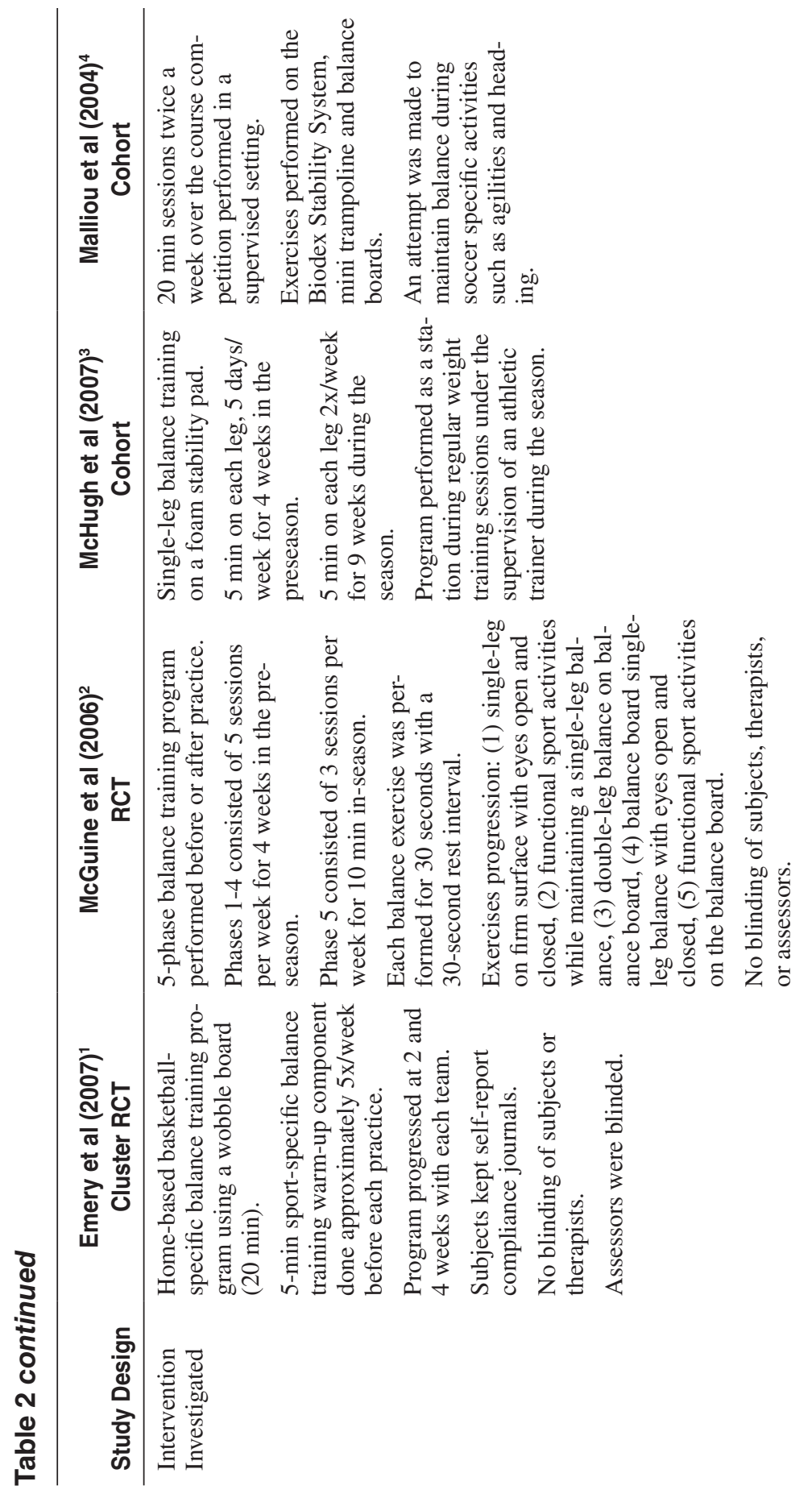



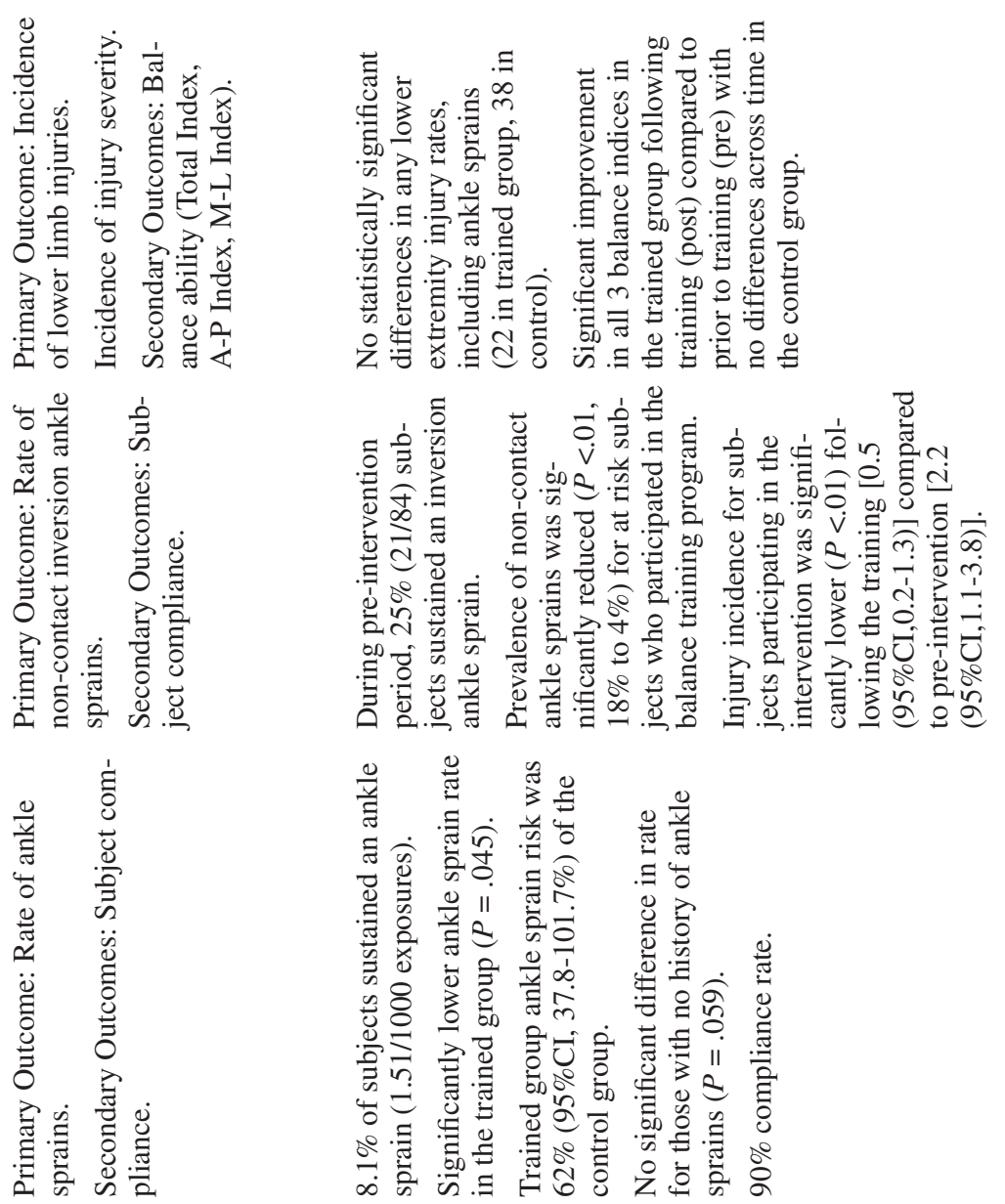

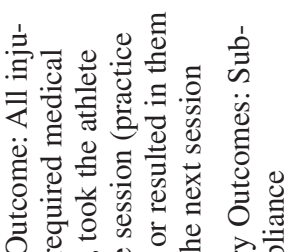

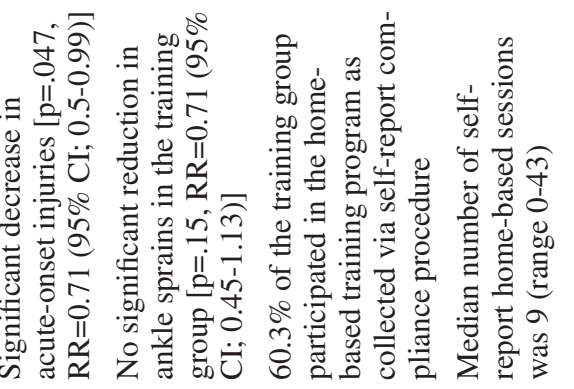

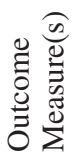

莺 


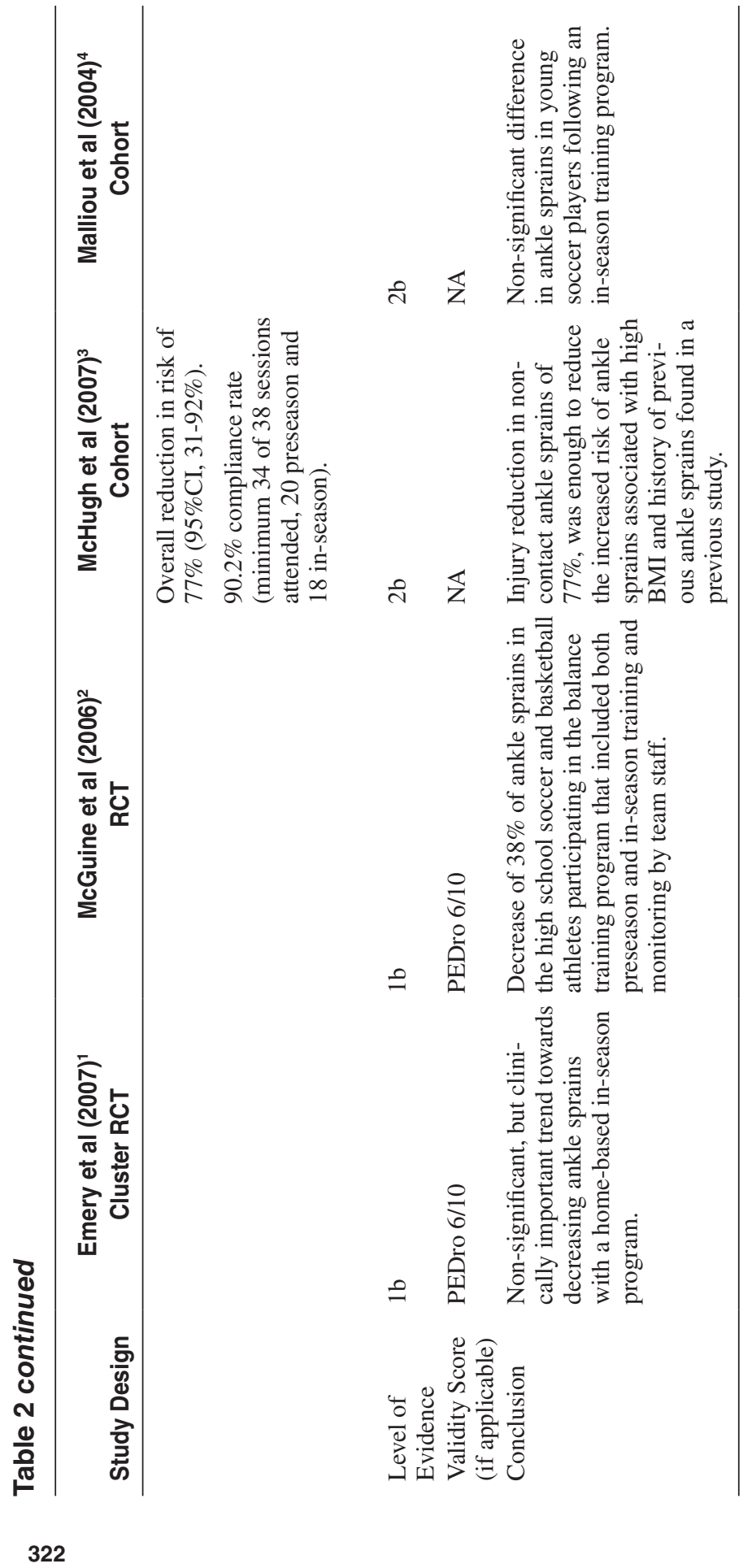


the timing of program implementation and subject compliance in completing the required training sessions.

The two studies ${ }^{2,3}$ that reported significant reductions in ankle sprains used balance training programs that had both preseason and in-season components and were performed in a team setting as part of the regular training or practice session, thus were supervised by a coach or athletic trainer. These two studies also reported better subject compliance ( $\geq 90 \%$ ). The home-based program, ${ }^{1}$ which included a short group training component, was dependent upon subjects performing the majority of the balance training exercises on their own. The findings of this study demonstrated lower subject compliance $(60.3 \%)$ with subjects participating, on average, in 9 training sessions (range $0-43$ ). The other study ${ }^{4}$ that did not find a reduction in ankle sprains only used an in-season program and did not report subject compliance.

Clinicians implementing injury prevention programs should consider including a supervised preseason phase that progresses from basic balance exercises (eyes open, firm surface) to more challenging exercises (eyes closed, uneven support surfaces, sport-specific drills). The program should then transition to a supervised in-season phase, where exercises continue to progress in difficulty, although at a lower volume and frequency than used in the preseason phase. Athletes should be educated that participating in each training session is important, and their compliance with the training program is an increased benefit to them.

Future research should include well-designed prospective studies that allow for blinding of the assessors to improve study quality, longer follow-up, and longer intervention periods that span across seasons or multiple years. Studies should also investigate the effect of balance training programs on injury rates in a variety of girls' and boys' sports, compare variations of program design (timing, frequency, duration, etc.), and determine the most effective balance progression. This CAT should be reviewed in two years to determine whether additional best evidence has been published that may change the clinical bottom line for this specific clinical question.

\section{References}

1. Emery CA, Rose MS, McAllister JR, Meeuwisse WH. A prevention strategy to reduce the incidence of injury in high school basketball: a cluster randomized controlled trial. Clin J Sport Med. 2007;17:17-24.

2. McGuine TA, Keene JS. The effect of a balance training program on the risk of ankle sprains in high school athletes. Am J Sports Med. 2006;34:1103-1111.

3. McHugh MP, Tyler TF, Mirabella MR, Mullaney MJ, Nicholas SJ. The effectiveness of a balance training intervention in reducing the incidence of noncontact ankle sprains in high school football players. Am J Sports Med. 2007;35:1289-94.

4. Malliou P, Gioftsidou A, Pafis G, Beneka A, Godolias G. Proprioceptive training (balance exercises) reduces lower extremity injuries in young soccer players. J Back Musculoskel Rehabil. 2004;17:101-104.

5. Emery CA, Cassidy JD, Klassen TP, Rosychuk RJ, Rowe BH. Effectiveness of a homebased balance-training program in reducing sports-related injuries among healthy adolescents: a cluster randomized controlled trial. CMAJ. 2005;172:749-54. 